Fletcher, F., Epstein, C. \& Jewell, P. I. (1953). J. gen. Microbiol. 8, 323-329.

\title{
The Antimycobacterial Activity of Tissue Extracts and Surface-active Agents in Dubos's Medium
}

\author{
By F. FLETCHER, C. EPSTEIN AND PATRICIA I. JEWELL \\ Benger Research Laboratories, Holmes Chapel, Cheshire
}

\begin{abstract}
SUMMARY: Purified tissue enzyme preparations, particularly bovine pancreatic deoxyribonuclease, have been shown to inhibit specifically pathogenic strains of Mycobacterium tuberculosis. Destruction of the enzymic activity did not influence this effect. Inhibition in Dubos's medium was markedly increased by Tween 80 but not by other surface active agents. Antibiotic potentiation by Tween 80 alone or combined with the tissue extracts was observed. The antimycobacterial activity of spermine was confirmed, but there was no evidence that it was present in our extracts and the inhibitory substance has not yet been identified.
\end{abstract}

Pirie (1935) reported that extracts of pig pancreas removed the pathogenicity of vaccinia and Rous tumour viruses. She suggested that the inactivation of some viruses by trypsin might be due to the action of fatty acids and lecithin, since crystalline trypsin prepared by Northrop (1932) had no effect on these viruses. Day \& Gibbs (1930) have described a canine pancreatic secretion obtained directly from the pancreatic duct, which inhibited tubercle bacilli (strain H37 Rv) but not staphylococci. More recently, Hirsch \& Dubos (1952) extracted spermine from beef kidney; this polyamine, which is widely distributed in animal tissues, was found to possess a remarkable specific inhibitory activity against pathogenic mycobacteria.

Soltys (1952) has reported the isolation of a substance from bovine tuberculous lymph nodes which inhibited bovine and human tubercle bacilli in vitro and in vivo. Although this factor was not identified, he suggested that it might be either a form of immune body or a substance similar to spermine.

During preliminary experiments with the medium of Dubos \& Davis (1946) containing $0.05 \%(\mathrm{w} / \mathrm{v})$ Tween 80 (polyoxyethylene sorbitan monoleate) and inoculated with Mycobacterium tuberculosis H37 Rv (NCTC 7416), we observed that the addition of bovine testicular hyaluronidase or beast pancreatic deoxyribonuclease completely inhibited growth; on replacing the surface active agent by $2 \%$ glycerol, a similar concentration of these enzymes possessed no inhibitory activity. Further investigations were therefore undertaken in order to elucidate this interesting observation.

\section{MATERIAIS AND METHODS}

\section{Preparation of tissue extracts}

The enzymes investigated for antibacterial activity were bovine pancreatic deoxyribonuclease, hog pancreatic lipase and bovine testicular hyaluronidase. The deoxyribonuclease was prepared from fresh bovine pancreas by extrac- 
tion with $0.2 \mathrm{~N}$-sulphuric acid and purified by fractionation with ammonium sulphate by the method described by McCarty (1946). The hyaluronidase was prepared from frozen bovine testes by extraction with $0.007 \%(\mathrm{w} / \mathrm{v})$ glacial acetic acid and purified by fractionation with ammonium sulphate by the technique adopted by Hahn (1943). The lipase was prepared from fresh hog pancreas which had been extracted with excess $\mathrm{N}$-butanol and the residue vacuum dried.

Sterile preparations were obtained by filtering aqueous solutions of the freeze-dried enzymes through Ford 'S.B.' sterilizing pads.

\section{Medium}

Basal medium was essentially that used by Dubos \& Davis (1946) and consisted of (w/v) : casein hydrolysate (Benger's Ltd, Holmes Chapel) $\mathbf{0 \cdot 1} \%$; $\mathrm{Na}_{2} \mathrm{HPO}_{4} .12 \mathrm{H}_{2} \mathrm{O}, 0.63 \% ; \mathrm{KH}_{2} \mathrm{PO}_{4}, 0.1 \% ; \mathrm{MgSO}_{4} .7 \mathrm{H}_{2} \mathrm{O}, 0.06 \%$; sodium citrate, $0 \cdot 15 \%$ in distilled water at $\mathrm{pH} 7 \cdot 0$. This medium was supplemented with $0.2 \%(\mathrm{w} / \mathrm{v})$ bovine albumin and either various surface active agents or $2 \%(w / v)$ glycerol.

Albumin solution was prepared by adjusting the $\mathrm{pH}$ of a $5 \%(\mathrm{w} / \mathrm{v})$ solution of bovine albumin Fraction V (Armour Laboratories Ltd., London) in $2 \%$ $(\mathrm{w} / \mathrm{v})$ sodium chloride to $7 \cdot 0$, warming the solution at $56^{\circ}$ for $30 \mathrm{~min}$. and sterilizing by filtration through a Ford 'S.B.' pad.

\section{Surface active agents}

(1) Tween 80 solution: the Tween 80 (polyoxyethylene sorbitan monoleate) used throughout the investigation was the purified product (G. 'T. Gurr Ltd., London), prepared specifically for use in media for the tubercle bacillus. Fresh $10 \%(\mathrm{w} / \mathrm{v})$ aqueous solutions of Tween 80 were prepared and autoclaved at $15 \mathrm{lb}$./sq.in. for $15 \mathrm{~min}$. immediately before use.

(2) Crill 20 : polyoxyethylene sorbitan monostearate (Croda Ltd., Goole).

(3) Carbowax: polyethylene glycol of molecular weight 600 (General Metallurgical and Chemical Co. Ltd., London).

(4) Triton A20: arylalkyl polyethoxyethanol (Rohm and Haas Co., Philadelphia).

The basal medium, in volumes of $5 \mathrm{ml}$., with or without glycerol, was distributed into $1 \mathrm{oz}$. McCartney bottles with metal screw caps and autoclaved at $15 \mathrm{lb}$./sq.in. for $15 \mathrm{~min}$; thereafter, the supplements of albumin and Tween 80 or other surface active agents were added aseptically.

\section{Culture and inoculum}

M. tuberculosis strain H37Rv (NCTC7416) was used; maintained on Petragnani (egg, potato-flour, skimmed milk) slopes. At monthly intervals the organism was subcultured into the liquid medium containing $0.05 \%(\mathrm{w} / \mathrm{v})$ Tween 80. The inoculum was well shaken with glass beads, allowed to stand for $1 \mathrm{hr}$. and then $0.1 \mathrm{ml}$. of the supernatant inoculated into $5 \mathrm{ml}$. of Dubos's medium. After 7-10 days incubation at $37^{\circ}$ a dispersed growth was obtained. 
The Breed count of this culture was adjusted so that $0.1 \mathrm{ml}$. delivered into $5 \mathrm{ml}$. of medium by means of a preset McClintock syringe (C. J. Hewlett and Co. Ltd., London) gave an inoculum of $5 \times 10^{5}$ to $1 \times 10^{6}$ organisms $/ \mathrm{ml}$.

\section{Chromatographic method}

The paper partition chromatographic technique described by Consden, Gordon \& Martin (1944) was employed to give a one-dimensional chromatogram on Whatman no. 54 paper, using the upper layer of $n$-butanol + acetic acid+water mixture $(4: 1: 5)$ as the mobile solvent. The paper was sprayed with ninhydrin $(0 \cdot 1 \%, \mathrm{w} / \mathrm{v}$, in butanol) and a comparison made with a sample of spermine phosphate (L. Light and Co. Ltd., Colnbrook, Bucks).

\section{RESULTS}

Inhibition of Mycobacterium tuberculosis in Dubos's medium by tissue extracts and surface active agents

In Dubos's medium containing $0.05 \%(\mathrm{w} / \mathrm{v})$ Tween 80, it was observed that the presence of bovine testicular hyaluronidase, bovine pancreatic deoxyribonuclease or hog pancreatic lipase, at a concentration of $3 \mathrm{mg}$. of enzyme in $5 \mathrm{ml}$. medium, completely inhibited the growth of $M$. tuberculosis (strain H37 Rv). On replacing the Tween 80 by other surface active agents, i.e. $0.01 \%(\mathrm{w} / \mathrm{v})$ Crill 20, $0.05 \%(\mathrm{w} / \mathrm{v})$ Carbowax, $0.1 \%(\mathrm{w} / \mathrm{v})$ bile salts, $0.05 \%$ $(\mathrm{w} / \mathrm{v})$ Triton A 20, or by $2 \%(\mathrm{w} / \mathrm{v})$ glycerol, no inhibition of growth occurred in the presence of the enzymes. It was further demonstrated that Tween 80 and Triton $\mathrm{A} 20$ at a tenfold increase in concentration $(0.5 \%, \mathrm{w} / \mathrm{v})$ possessed no inhibitory activity in the absence of the tissue extracts.

Inhibition of $\mathbf{H} 37 \mathrm{Rv}$ was subsequently observed, even in the absence of Tween 80 and the other detergents, when a sixfold increase in concentration of pancreatic deoxyribonuclease and lipase was used.

Similar observations were made when Dubos's medium was supplemented with $10 \%(\mathrm{w} / \mathrm{v})$ horse serum.

The potentiation of the activity of penicillin against $\mathbf{H} 37 \mathbf{R v}$ by $0.05 \%$ (w/v) Tween 80 reported by Kirby \& Dubos (1947) was confirmed, but the surface active agent Triton A20 failed to enhance the inhibitory activity of either penicillin or the enzymes. It was observed, in addition, that pancreatic deoxyribonuclease, in the presence or absence of Tween 80, was capable of increasing the antimycobacterial activity of both penicillin and streptomycin, but similar synergistic activity could not be demonstrated with all the preparations of deoxyribonuclease examined. These results are shown in Table 1.

\section{Enzymic activity and inhibitory effect}

It was observed that several preparations of pancreatic deoxyribonuclease, although exhibiting similar enzymic activity when assayed by the reduction in viscosity of a deoxyribonucleic acid substrate (McCarty, 1946), possessed varying antimycobacterial activity, which in most cases was considerably potentiated by Tween 80 . However, one preparation (batch $\mathrm{C}$ ) produced no 
inhibition when present in a concentration of $25 \mathrm{mg} . / 5 \mathrm{ml}$., although it possessed an enzymic activity similar to the other preparations (batches A, B and D). This is shown in Table 2 .

Table 1. Potentiation of activity of streptomycin and penicillin against Mycobacterium tuberculosis $H 37 R v$ by pancreatic deoxyribonuclease (batch $D$ )

Minimal antibiotic concentration (units/ml.) to cause inhibition after 3 weeks incubation at $37^{\circ}$

(1) No Tween 80 or D-ase

(2) $0.025 \%$ Tween 80 . No D-ase

(3) $0.01 \%$ Tween 80 . No D-ase.

(4) $0.025 \%$ Tween $80+3 \mathrm{mg} . / 5 \mathrm{ml}$. D-ase

(5) $0.01 \%$ Tween $80+3 \mathrm{mg} . / 5 \mathrm{ml}$. D-ase

(6) No Tween $80+3 \mathrm{mg}$. $/ 5 \mathrm{ml}$. D-ase

(7) $0.05 \%$ Triton A 20. No D-ase

(8) $0.05 \%$ Triton A $20+3 \mathrm{mg}$. D-ase $/ 5 \mathrm{ml}$.

\begin{tabular}{|c|c|c|c|c|c|c|c|c|}
\hline \multicolumn{9}{|c|}{ at $37^{\circ}$} \\
\hline \multicolumn{5}{|c|}{ Penicillin } & \multicolumn{4}{|c|}{ Streptomycin } \\
\hline 1000 & 100 & 10 & 1 & 0 & 1 & 0.5 & $0 \cdot 25$ & $0 \cdot 125$ \\
\hline+ & + & + & + & + & - & + & + & + \\
\hline- & - & + & + & + & - & - & + & + \\
\hline- & + & + & + & + & - & + & + & + \\
\hline- & - & - & - & - & - & - & - & - \\
\hline - & - & - & + & + & - & - & - & - \\
\hline - & - & + & + & + & - & + & + & + \\
\hline+ & + & + & + & + & - & + & + & + \\
\hline- & + & + & + & + & - & + & + & + \\
\hline
\end{tabular}

Full growth $=+$; no growth $=-$.

Table 2. Minimal concentration of three preparations $(A, B, D)$ required for complete inhibition of $\mathbf{M}$. tuberculosis $(H \mathbf{3} 7 \boldsymbol{R} v)$ with and without the addition of $0.05 \%$ Tween 80 after 3 weeks' incubation at $37^{\circ}$

\begin{tabular}{l}
\multicolumn{1}{c}{ Culture medium } \\
Dubos's ('Tween 80 absent) \\
Dubos's $+0.05 \%(w / v)$ Tween 80
\end{tabular}

\begin{tabular}{|c|c|c|}
\hline \multicolumn{3}{|c|}{ Mg./5 ml. broth } \\
\hline A & $\mathbf{B}$ & $\mathbf{D}$ \\
\hline 25 & 20 & 18 \\
\hline 6 & 3 & 3 \\
\hline
\end{tabular}

Growth inhibition was later shown to be independent of enzymic activity since a similar effect occurred after the enzymes had been destroyed by heating at $56^{\circ}$ for $30 \mathrm{~min}$. on two successive days.

\section{Specificity of the active inhibitory substance}

The tissue extracts were found to possess activity against a virulent bovine strain of $M$. tuberculosis similar to that described for H37 Rv. However, using high concentrations $(18 \mathrm{mg} . / 5 \mathrm{ml}$.) of the freeze-dried extracts in the presence or absence of $0.05 \%(\mathrm{w} / \mathrm{v})$ Tween 80 , no inhibition could be demonstrated against the saprophytic $M$. phlei (NCTC525) or against Salmonella typhi (NCTC785), Streptococcus salivarius (NCTC 445), Bacterium coli-commune (NCTC 86), Pseudomonas aeruginosa (NCTC7244), Klebsiella pneumoniae 41 (NCTC 7242) and Staphylococcus aureus (NCTC6571).

\section{Comparison of bovine deoxyribonuclease with spermine}

The antimycobacterial activity of pancreatic deoxyribonuclease was compared with spermine phosphate, which can be isolated from various tissues, including the pancreas (Fearon, 1947). Hirsch \& Dubos (1952) claimed that 
a concentration of $\mathbf{0 . 1 2 5} \mathrm{mg}$. of spermine phosphate in $5 \mathrm{ml}$. of Dubos's medium inhibited the growth of pathogenic mycobacteria but had no effect on other pathogenic organisms, and this was confirmed. In contrast to the findings with our tissue extracts, the activity of spermine was observed to be unaffected by the addition of 'Tween 80 to Dubos's medium.

Chromatographic analysis of preparation B (see Table 2) of pancreatic deoxyribonuclease failed to reveal the presence of spermine, and fractionation of this material by methods employed by Hirsch \& Dubos, with a view to isolating spermine, proved unsuccessful, since the various fractions obtained failed to correspond chromatographically to spermine.

\section{DISCUSSION}

Arising from the work of Dubos (1945) and Dubos \& Davis (1946), addition of the synthetic non-ionic detergent, Tween 80 , to defined culture media for virulent tubercle bacilli has been widely adopted. Tween 80 appears to exert a stimulatory effect on the growth of tubercle bacilli and produces a diffuse homogeneous growth instead of the usual granular floccules. This surface active agent probably accelerates the growth of the organism by assisting the absorption of nutrients through the cell wall; at the same time, it produces a conveniently dispersed suspension of the tubercle bacilli. In a similar manner, Tween 80 could permit a more intimate contact between an antibacterial agent and the surface of the cell wall, and even enhance intracellular penetration of the inhibitory substance.

Youmans \& Youmans (1948) reported that the presence of Tween 80 in a defined medium increased the tuberculostatic activity of fifteen (including chloramphenicol) out of twenty compounds, decreased the activity of three compounds and had no effect on two compounds.

Potentiation of the antibiotic activity of penicillin (Kirby \& Dubos, 1947) and streptomycin (Fisher, 1948) by Tween 80 against $M$. tuberculosis $\mathbf{H} 37 \mathbf{R v}$ has been previously reported; Bliss \& Warth (1950) observed a similar effect on the activity of polymyxin D against Bact. coli. In our investigations, it seemed possible that Tween 80 likewise influenced the antibacterial activity of the purified enzyme preparations. In view of the reported potentiation of antibacterial agents by Tween $\mathbf{8 0}$ and our failure to obtain a similar effect with other surface active agents, it is of interest to suggest reasons for this specific property of Tween 80 .

Triton A20 is a powerful non-ionic wetting agent which, at a concentration of $0.05 \%(w / v)$ in Dubos's medium, ensures a rapid and dispersed growth of $M$. tuberculosis, but we observed no effect on the activity of various antimycobacterial agents.

A significant difference between Triton A20 and Tween 80 is that the former contains no fatty acid group. There are grounds for suggesting that the oleic acid group in the Tween 80 molecule may play a delicate role in the metabolism of the tubercle bacillus since esters of lauric and palmitic acid (Tween 20 and Tween 40) have been shown to be inhibitory (Dubos \& Davis, 1946). In the present investigation, Crill 20, a stearate, was itself inhibitory 
at $0.05 \%(\mathrm{w} / \mathrm{v})$, permitted growth at $0.01 \%(\mathrm{w} / \mathrm{v})$, but failed to potentiate the activity of tissue extracts at the latter concentration. Dubos \& Middlebrook (1947) have reported that long chain fatty acids, and oleic acid in particular, exert a dual effect on $M$. tuberculosis. In most media, particularly in the absence of albumin, their soaps are markedly inhibitory, but when supplied to the medium in a non-toxic form, for example as a water dispersable ester such as Tween 80 , they can act as nutrients for mycobacteria.

All strains of tubercle bacilli were found by Dubos (1946) to be capable of utilizing oleic acid, but human and bovine strains are so susceptible to oleic acid that it is often very difficult to choose amounts sufficient to stimulate growth appreciably without reaching the toxic concentration. In view of the delicate balance which exists in regard to the oleic acid requirements of the pathogenic mycobacteria, it would appear advisable to confine the use of Tween 80 to the preparation of a homogeneous inoculum, and perhaps serious consideration should be given to its replacement by Triton A 20.

Hirsch \& Dubos (1952) isolated a specific antimycobacterial factor, spermine, from beef kidney, but this substance is widely distributed in animal tissues (Table 3) and is found in greatest amounts in the prostate gland.

Table 3. Representative values of spermine in $\mathrm{mg} .100 \mathrm{~g}$. fresh tissue

(from Fearon, 1947)

$$
\begin{array}{cccl}
\text { Human prostate } & 130 & \text { Human liver } & 10 \\
\text { Human pancreas } & 16 & \text { Ox pancreas } & 25-30 \\
\text { Testicle, spleen, kidney 1-7 } &
\end{array}
$$

We have not been able to demonstrate the presence of spermine in the pancreatic enzyme preparations used in this investigation, and it would appear that an active thermostable principle, other than spermine, exists in certain enzymic tissue extracts which is capable of a highly specific antimycobacterial action in the presence of serum proteins. It is recognized that pancreatic tuberculosis is a rare disease and it may be suggested that this is due to the presence in the pancreas of a single, or several specific, antimycobacterial substances.

We wish to express our thanks to the Directors of Bengers' Ltd. for permission to publish these results, and to Dr C. Giles of the City General Hospital, Newcastleunder-Lyme and Dr A. J. McCall of the North Staffordshire Royal Infirmary, Stoke-on-Trent, for their interest in this work.

\section{REFERENCES}

Bliss, E. A. \& WARTh, P. T. (1950). The effect of surface active agents on antibiotics; an informal report. Ann. N.Y. Acad. Sci. 53, 38.

Consden, R., Gordon, A. H. \& Martin, A. J. P. (1944). Qualitative analysis of proteins: a partition chromatographic method using paper. Biochem. J. 38, 224.

DAY, A. A. \& GibBs, W. M. (1930). The action of pancreatic juice on bacteria. J. infect. Dis. 46, 26.

Dubos, R. J. (1945). Rapid and submerged growth of Mycobacteria in liquid media. Proc. Soc. exp. Biol., N.Y. 58, 361. 
Duвos, R. J. (1946). Effect of long chain fatty acids on bacterial growth. Proc. Soc. exp. Biol., N.Y. 63, 56.

Dubos, R. J. \& Davis, B. D. (1946). Factors affecting the growth of tubercle bacilli in liquid media. J. exp. Med. 83, 409.

Dubos, R. J. \& Middlebrook, G. (1947). Media for tubercle bacilli. Amer. Rev. Tuberc. 56, 334.

Fearon, W. R. (1947). Introduction to Biochemistry, p. 417. London: Heinemann.

Fisher, M. W. (1948). Sensitivity of tubercle bacilli to streptomycin; an in vitro study of some factors affecting results in various test media. Amer. Rev. Tuberc. 57, 58.

HAhN, L. (1943). Preparation of hyaluronidase from bull testes. Biochem. Z. 315, 83.

Hirsch, J. G. \& Dubos, R. J. (1952). The effect of spermine on tubercle bacilli. J. exp. Med. 95, 191.

Kirby, W. M. M. \& Dubos, R. J. (1947). Effect of penicillin on the tubercle bacillus in vitro. Proc. Soc. exp. Biol., N.Y. 66, 120.

McCarTy, M. (1946). Purification and properties of deoxyribonuclease isolated from beef pancreas. J. gen. Physiol. 29, 123.

Northrop, J. H. (1932). The preparation of crystalline trypsin. J. gen. Physiol. $16,313$.

Pinie, A. (1935). The effects of extracts of pancreas on different viruses. Brit. $J$. exp. Path. 16, 497.

Soltys, M. A. (1952). An antituberculous substance in tuberculous lymph nodes. Nature, Lond. 169, 1095.

Youmans, A. S. \& Youmans, G. P. (1948). The effect of Tween 80 in vitro on the bacteriostatic activity of twenty compounds for Mycobacterium tuberculosis. J. Bact. 56, 245. 